\title{
Research models and methods in legal translation
}

\section{Lucja Biel}

University of Warsaw, Poland

1.biel@uw.edu.pl

\section{Jan Engberg}

University of Aarhus, Denmark

je@asb.dk

The introduction presents an overview of traditional research methods in Legal Translation Studies and discusses new developments as represented by the papers comprised in the special issue. The predominant methodology is corpus-based; there is a clear shift from qualitative to quantitative methods. Corpus-based methods are applied to the study of local phenomena, such as terms or phrasemes, and of global phenomena, such as genres and macrogenres, as well as they analyse practical decisions made by legal translators with a view to developing new tools and resources for translators. Other directions include: the application of comparative law methods, sociology of translation and Critical Discourse Analysis. Overall, there is growing interest in the communicative, pragmatic, cognitive and social aspects of legal translation. As the papers demonstrate, research into legal translation requires methodological eclectism and triangulation, as well as further integration along the interdisciplinary lines.

One of the areas of the study of language, as applied to different fields of practice, which has boasted the highest degree of interest in recent years is that of language usage in legal settings. On this topic alone, many conferences are held in different parts of the world, specialist journals have been called into life, and relevant educational programmes have been introduced. One of the central fields for practical work on issues of language usage (even the use of multiple languages) in the sphere of law is that of translation.

This special issue of Linguistica Antverpiensia, New Series (LANS) - Themes in Translation Studies aims to connect to the ongoing surge of interest in the field and at the same time to contribute to developments in this sphere of the discipline of specialised translation. The intention is to track recent developments in Legal Translation Studies triggered by new methodologies and recent developments in theoretical 
models and approaches and to test the explanatory power and potential of such approaches to uncover the nature of legal translation.

Although Legal Translation Studies covers all types of both pure and applied research in Holmes' map of translation studies (see Holmes 1988/2000), the discipline has traditionally focused on what Holmes classifies as product-oriented descriptive research, that is, the description of the phenomena in legal translation by analysing existing translations research in the area has been predominantly qualitative rather than quantitative. In the past decade, more interest has been shown in processoriented descriptive research - for example, Think-Aloud Protocols aimed at understanding the processes that occur in a legal translator's mind (see Hjort-Pedersen \& Faber, 2010). Function-oriented studies aimed at studying the cultural and social aspects of translation reception in target legal cultures (see Lambert 2009) have also gained prominence.

Compared to other types of translation, the literature on legal translation contains relatively little reflection on its methods and approaches, notable (early) exceptions being the work of Šarčević (1997, 2000) and Garzone (2000). This may be partly due to the fact that research into legal translation is strongly fragmented into enclaves along two lines: of researchers' disciplines and of the languages or countries in which research is published. Research has been carried out separately by translation scholars, terminologists, linguists and comparative lawyers, who tend to approach legal translation through a methodological lens and in line with interests prevalent in their disciplines. For example, while lawyers are more interested in the theoretical aspects of comparing legal systems and legal consequences (see de Groot, 1988; Pommer, 2006), translation scholars often embark on a relentless quest for equivalence and solve problems practically (see Alcaraz \& Hughes, 2002; Cao, 2007), or they attempt to define legal translation (Asensio, 2007; Harvey, 2002). Linguists' primary interest lies in the semantic, syntactic, pragmatic and discursive aspects of legal translation (e.g., Bhatia $(1997,2004)$ on genres in translation).

Until recently, there has been little interaction between the disciplines, and yet further interdisciplinary integration of research findings and perspectives is needed (see Engberg, 2013) to obtain a multidimensional view of legal translation. The second cause of fragmentation has resulted in language-specific enclaves with their own research traditions, methods and priorities built around English, French, German, Spanish and Italian. These enclaves have started to open up and inform each other to a greater extent in the past two decades. Another potential cause of fragmentation is the unique nature of the translation of multilingual law, which, as argued by Kjær (2007) with reference to EU law, should become an independent research field with its own theoretical framework because traditional theories of legal translation are inadequate in accounting for it. This area was first strongly influenced by Canadian and Swiss scholars (e.g., Gémar, 1979), and then by scholars working on 
the translation of EU law (Baaij, 2012; Felici, 2010; Kjær, 2007; McAuliffe, 2011; Šarčević, 1997, 2007;;;), including aspects such as its hybridity (McAuliffe, 2011), the institutionality of EU translation (see Koskinen's ethnographic approach (2008)), and studies in translationshaped EU language (Caliendo, 2007; Caliendo, Di Martino, \& Venuti, 2005; Dollerup, 2001; Foley, 2002; Goffin, 1994;;;; Pozzo, 2012).

One of the decisive factors affecting research into legal translation is the fact that it is an operation not only between two or more languages but, above all, between distinct legal systems and legal cultures. Legal systems, which have their own history, patterns of reasoning and social and moral background, develop their own systems of concepts adjusted to their own needs. This results in the system-bound nature of legal terminology (Šarčević, 1997, p. 232) and the considerable incongruity between the systems that requires translators to build compensating "terminological bridges" (Weigand, quoted in Šarčević, 2012, p. 13). Terminological incongruity, the (un)translatability of legal terms, as well as such compensating "terminological bridges" - that is, strategies for and techniques of establishing equivalence between terms from different legal systems - have traditionally been one of the key areas of research into legal translation. This strand of research is closely related to terminography and is informed by practically oriented research into legal terms for translation purposes such as the preparation of legal dictionaries or terminological databases (see Chromá, 2004; Sandrini, 1996; Heid, Fritzinger, Hauptmann, Weidenkaff, \& Weller, 2008; Orozco \& Sánchez Gijón, 2011). In line with recent developments in the field of terminology (see Cabré Castellví, 2003, pp. 168-171; L'Homme, Heid, \& Sager, 2003, p. 153; Temmerman, 2000, pp. 4-38), studies in legal terminology have experienced a shift from onomasiological to semasiological approaches and a growing interest in the social, cognitive and communicative aspects of terms (see, for example, Antia, 2001; Engberg, 2002; Tessuto, 2008).

This special issue of LANS attests to the growing interest in and awareness of research methods, tools and models in Legal Translation Studies. In what follows, we first briefly introduce the papers in this special issue and subsequently describe some of the recent developments of which the studies are examples.

This special issue consists of the following ten articles:

- $\quad$ Patricia Vanden Bulcke's article (Dealing with deontic modality in a termbase: The case of Dutch and Spanish legal language) presents a corpus-based termbase intended for translators. The purpose of the database is to offer information about the application of deontic modality in Dutch and Spanish legal texts relevant to making decisions about the most relevant target language (TL) renderings of source language (SL) elements. The 
article combines genre and corpus linguistics with comparative law.

- The article A genre analysis approach to the study of the translation of court documents by Anabel Borja Albi treats the process of establishing a genre-based IT platform that holds information on more general textual conventions relevant to translators. The information included is founded upon corpusbased analyses.

- In her article Die notarielle Urkunde im italienisch-deutschen Vergleich: Überlegungen zur Übersetzung von Immobilienkaufverträgen, Eva Wiesmann gives an overview of the generic particularities of notarial documents between German and Italian. She applies theoretical approaches and methods from comparative law in order to demonstrate reflections of differences between the legal systems underlying the notarial documents in concrete formulations.

- Federical Scarpa's article Investigating legal information in commercial websites: The terms and conditions of use in different varieties of English also treats an aspect of comparative differences between legal systems. She investigates the impact of the translation into English of legal provisions to be used in nonEnglish contexts such as internationally accessible commercial websites. The work is based on comparative corpus analyses of English as a Native Language versus English as a Lingua Franca.

- $\quad$ The article Exploring near-synonymous terms in legal language. A corpus-based, phraseological perspective by Stanislaw GoźdźRoszkowski focuses on the problem of translators' having to distinguish between near-synonyms and also between them in translations. He adopts a phraseological approach oriented towards assessing degrees of synonymy in legal language and based on corpus analysis.

- Anna Jopek-Bosiacka adopts a macro perspective on legal translation. In her contribution, Comparative law and equivalence assessment of system-bound terms in EU legal translation, she presents the results of a study of legal translation strategies applied in EU settings. The applied framework for assessing the strategies is comparative law and the methods it employs to make conceptual comparisons.

- The article Legal translation and "traditional" comparative law: Similarities and differences by Ingrid Simonnæs concentrates upon the situation in which a translator will have to find creative solutions to a translation due to the novelty of the concepts to be translated. She focuses especially on possible valuable impacts on this process from the theory of comparative law and from the application of methods from comparative law. 
- In her article, Fine tuning style and precision: Adapting directive citations to Finnish statutes, Aino Piehl investigates the macro aspect of transposition strategies in connection with legal translation in EU settings. Her interest lies especially in the aspect of multinational law (e.g. the law of the EU) encountering national law (e.g. the Finnish) in the process of transposing (i.e. introducing the community rules in national law) directives. The applied methods mainly come from corpus analysis with a special emphasis on the search for n-grams.

- The article Towards a new research model in legal translation: Future perspectives in the era of asymmetry by $\mathrm{M}^{\mathrm{a}}$ Carmen África Vidal Claramonte discusses the impact on the concept and the quality standards of legal translation that emerges when we take post-structuralist concepts seriously. Consequences will also be to study the actual clashes and asymmetries between cultures, based upon the dynamicity of meaning and the idea of meaning as inherently constructed.

- Ioannis E. Saridakis is interested in the emergence and evolution of international legal language semantics. In his article, Crosslinguistic semantics of international law: A corpus-informed translation of A. Cassese's International Law into Greek he investigates the concepts developed in a book on international law and its translation. He is especially interested in the power relations governing the development of the investigated concepts and therefore draws upon methods derived from Critical Discourse Analysis.

- In order to locate the articles in the landscape of recent developments in the field of Translation Studies, in the remainder of our introduction we present those developments that are represented in this special issue.

The most frequently represented promising new approach is constituted by corpus-based methodologies and their combination with other methods. Corpora have been intensely applied in Linguistics and Translation Studies as an empirical and data-driven approach that allows for reduced speculation and offers the potential to verify hypotheses systematically on large collections of texts. Corpus-based methodologies have changed the way we handle data but, above all, have shifted attention from the study of words to the study of patterns, emphasising that language use is highly patterned and that such patterns are cognitively motivated (see Stubbs, 2004). Legal language, which is notorious for its formulaicity, standardisation, petrification and rituals, seems to be well suited to this type of analysis. Overall, corpus-based studies of legal translation reflect and strengthen the new turn in Translation Studies, referred to by Michael Cronin (2010)as "the 
technological turn", connected with the ubiquity of computers, new forms of translation practice and more sophisticated research tools and software.

As the studies included in this issue show, corpus-based methods of investigating legal language benefit from methodological triangulation and the combination of quantitative and qualitative methods. In our case we present combinations of corpus-based methodologies with work on termbases (Vanden Bulcke) and on the conceptual or terminological component of the translation process (Saridakis), combinations with the study of English as a Native Language versus English as a Lingua Franca (i.e., of translations of non-English law into English) in the legal field (Scarpa), with the quest for assessing degrees of synonymy between legal concepts (Goźdź-Roszkowski), with the investigation of linguistic regularities when transposing EU legal texts into Finnish (Piehl) and with the study of genre systems and metagenres in institutional settings within the genre-analysis approach (Borja Albi).

All these approaches have a different relation to the legal field (ranging from the more centrally translation-related question of formulation to aspects of comparative law), but in some way or another they all use corpus-based methodologies either to get to know more detail about different kinds of legal language (as a working tool for translation) or to get to know more about the differences between translated and nontranslated legal texts. The articles thus touch upon aspects treated in the literature under such headings as the hypotheses of translation universals - distinctive features of translation resulting from constraints unique to the translation process, researched on comparable corpora (Baker, 1993, 1995) - as well as the textual fit of translations (see Chesterman, 2004), that is, how translated law and other legal texts differ from non-translated language, with a view to shedding light on the communicative dimension of translations.

A recent direction of research represented in this special issue is legal translation in multilingual and institutionalised settings, which, as emphasised in the literature, is a rare object of study within Translation Studies. In the enlarged European Union, legal translation participates in the construction of new societies, having a social, cultural and political dimension. Owing to its unprecedented multilingualism, institutionality and hybridity, EU translation has challenged some central concepts of Translation Studies with its fluid and non-final source texts, concurrent drafting and translation, collective translation processes, and the replacement of source text and target texts by authentic language versions. The article by Jopek-Bosiacka is the one most directly approaching this direction, because it investigates translation strategies applied in the Polish EU translation practice related to European Court of Justice judgments. The special theoretical approach introduced here is comparative law. So, owing to the fact that translation in the EU context must be seen as the actual creation of law (due to the fact that all translated texts become originals, once officially adopted), different 
versions are assessed on the basis of methods from comparative law. The micro-comparison method applied by Jopek-Bosiacka may also function as a quality assessment tool.

Another pertinent question in the context of the EU is how EU law influences the language of national law at the conceptual, syntactic and textual levels and how it can be tested empirically. Here, the already mentioned article by Aino Piehl is a case in point. She proposes the use of the corpus-based method of detecting n-grams in text as an instrument for measuring the degree to which Finnish versions of EU legislation ("translations") influence the language of the national Finnish statutory texts that are used to implement the EU legislation in Finland.

Two articles (by Saridakis and by Vidal Claramonte) represent a development which has been under way for some time in the field of the sociology of translation (see, for example, Wolf \& Fukari, 2007) and also in the field of law, but which is only beginning to enter the study of legal translation. Both articles are interested in the power relations that influence legal discourse and the role of translation in this respect. And both introduce critical and post-structuralist approaches as means of dealing with this aspect of the interaction between translation and law. The main difference between more traditional approaches to legal translation and the post-structuralist approaches applied in these articles concerns the perspective of semantic stability. Whereas traditional approaches tend to see meaning as fairly stable and independent of "meaners", the post-structuralist approach takes seriously the instability of meaning and the importance of every instance of language use and choice of formulation. This means that it becomes relevant to study individual translations, to see translation choices as part of struggles both over meaning inside (legal) cultures and across them, and also to include in models of practical translation the power of translations to change meaning and to question the status quo.

Finally, a number of papers show an interest in the practical decisions made by legal translators. Their objective is to develop novel methods, tools and resources for translators to optimise the translation process. Inevitably, such resources tend to make use of new technologies, including tools based on comparable and parallel corpora. The decisionmaking process is assisted by corpora applied at the micro level as an analytical tool, by dedicated termbases, as well as by complex advanced tools that integrate corpora with a knowledge base. In respect of the micro level, Goźdź-Roszkowski develops a corpus-based phraseologically oriented method for disambiguating near-synonymous legal terms. He uses a multi-genre corpus of American legal texts to clarify the meaning of semantically related terms by analysing their phraseological behaviour. This method can be used both to improve the translator's understanding of SL terms and to assess their potential TL equivalents. Another microlevel method is proposed by Simonnæs, who applies comparative law to a 
discussion of the creativity necessary to translating new legal concepts related to same-sex marriages in a Norwegian regulation.

Regarding tools, this line of research is represented by two projects: JuriGenT by Vanden Bulcke and JudGENTT by Borja Albi. The JuriGenT project involves corpus-driven terminography (as does the project underlying Saridakis's paper, working with a corpus-driven database) and demonstrates how comparable corpora may be used to identify the cross-linguistic variation of deontic modality in articles of association and to encapsulate it in termbases intended for translators. Such information raises translators' awareness of asymmetries and helps them to make an informed choice of a conventional solution for a TL. Borja Albi reports on the JudGENTT action research project designed to create an online platform for the multilingual management and translation of court documents related to four legal systems. The platform is based on an innovative solution to combine comparable and parallel corpora of criminal court documents integrated with more traditional resources such as glossaries of terminology and phraseology, bibliographies, and contextual information on criminal procedure. Such integration of various resources in a single platform and the possibility of retrieving information with a built-in search facility is a great step forward for Spanish legal translators and in general for the information-mining process during translation. Both projects are generalisable to other contexts and can be replicated for other language pairs. It is also worth noting that the greatest advantage of new tools is their potential to raise translators' awareness of SL and TL generic conventions. It is not accidental that the authors work on genre-based corpora, predicted by Bhatia, Langton and Lung (2006) to be of importance in legal language studies, because they contribute to developing more focused resources, including information on genre variation, than traditional legal dictionaries.

To sum up, this special issue demonstrates that studies in legal translation require not only methodological eclectism and triangulation, but also interdisciplinarity. Similarly to other areas of Translation Studies, known also as an interdiscipline or a polidiscipline (see Bassnett, 2012; Brems Meylaerts, \& van Doorslaer, 2012; Gentzler, 2003;), research into legal translation is stimulated by developments in neighbouring disciplines, in particular legal studies, comparative law, terminology and various brands of (functional) linguistics. These contacts have both opened up new research perspectives and brought into life new themes, concepts and methods. In addition, they have shifted the focus from the traditional areas of investigation, such as the incongruity of legal terms and the limits of translatability, to the communicative, pragmatic, cognitive and social aspects of legal translation. Another observable development is a shift from prescription to description, a shift which has been observed in corpus-based translation studies, thanks to the possibility offered by corpus analysis to observe and build on solutions used by translators (see Baker, 1995, p. 231). 
Owing to its unique links to other disciplines, the intensified research activity and institutionalisation, the field of Legal Translation Studies is evincing a growing autonomy and independence within the wider sphere of Translation Studies.

\section{References}

Alcaraz, E. V., \& Hughes, B. (2002). Legal translation explained. Manchester: St. Jerome.

Antia, B. E. (2001). Terminological investigations into specialized knowledge and texts: A case study of legislative discourse. Terminology, 7(1), 5-29.

Asensio, R. M. (2007). Specialised translation: A concept in need of revision. Babel, $53(1), 48-55$.

Baaij, C. J. W. (2012). Fifty years of multilingual interpretation in the European Union. In L. M. Solan \& P. M. Tiersma (Eds.), The Oxford handbook of language and law. Oxford: Oxford University Press. DOI: 10.1093/oxfordhb/9780199572120.013.0016.

Baker, M. (1993). Corpus linguistics and translation studies: Implications and applications. In M. Baker, G. Francis, \& E. Tognini-Bonelli (Eds.), Text and technology: In honour of John Sinclair (pp. 233-250). Amsterdam: John Benjamins.

Baker, M. (1995). Corpora in translation studies: An overview and some suggestions for future research. Target, 7(2), 223-243.

Bassnett, S. (2012). Translation studies at a cross-roads. Target, 24(1), 215-225.

Bhatia, V. K. (1997). Translating legal genres. In A. Trosborg (Ed.), Text typology and translation (pp. 203-213). Amsterdam: John Benjamins.

Bhatia, V. K. (2004). Worlds of written discourse. London: Continuum.

Bhatia, V. K., Langton, N. M., \& Lung, J. (2004). Legal discourse: Opportunities and threats for corpus linguistics. In U. Connor \& T. A. Upton (Eds.), Discourse in the professions: Perspectives from corpus linguistics (pp. 203-231). Amsterdam: John Benjamins.

Brems, E., Meylaerts, R., \& van Doorslaer, L. (2012). A discipline looking back and looking forward: An introduction. Target, 24(1), 1-14.

Cabré Castellví, M. T. (2003). Theories of terminology: Their description, prescription and explanation. Terminology, 9(2), 163-199.

Caliendo, G. (2007). Modality and communicative interaction in EU law. In C. N. Candlin \& M. Gotti (Eds.), Intercultural aspects of specialized communication (pp. 241-259). Bern: Peter Lang.

Caliendo, G., Di Martino, G., \& Venuti, M. (2005). Language and discourse features of EU secondary legislation. In G. Cortese \& A. Duszak (Eds.), Identity, community, discourse: English in intercultural settings (pp. 381-404). Bern: Peter Lang.

Cao, D. (2007). Translating law. Clevedon: Multilingual Matters.

Chesterman, A. (2004). Hypotheses about translation universals. In G. Hansen, K. Malmkjær, \& D. Gile (Eds.), Claims, changes and challenges in translation 
studies: Selected contributions from the EST Congress, Copenhagen 2001 (pp. 1-13). Amsterdam: John Benjamins.

Chromá, M. (2004). Legal translation and the dictionary. Tübingen: Max Niemeyer.

Cronin, M. (2010). The Translation crowd. Revista Tradumàtica, 8. Online: http://www.fti.uab.es/tradumatica/revista/num8/articles/04/04central.htm.

Dollerup, C. (2001). Complexities of EU language work. Perspectives: Studies in Translatology, 9(4), 271-292.

Engberg, J. (2002). Legal meaning assumptions: What are the consequences for legal interpretation and legal translation? International Journal of the Semiotics of Law, 15(4), 375-388.

Engberg, J. (2013). Comparative law for translation: The key to successful mediation between legal systems. In A. Borja Albi \& F. Prieto Ramos (Eds.), Legal translation in context: Professional issues and prospects (pp. 9-25). Oxford: Peter Lang.

Felici, A. (2010). Translating EU law: Legal issues and multiple dynamics. Perspectives: Studies in Translatology, 18(2), 95-108.

Foley, R. (2002). Legislative language in the EU: The Crucible. International Journal for the Semiotics of Law, 15, 361-374.

Garzone, G. (2000). Legal translation and functionalist approaches: A contradiction in terms? Geneva: Actes. Online: www.tradulex.org.

Gentzler, E. (2003) Interdisciplinary connections. Perspectives: Studies in Translatology, 11(1), 11-24.

Gémar, J.-C. (1979). La traduction juridique et son enseignement: Aspects théoriques et pratiques. Meta: Translators' Journal, 24(1), 35-53.

Goffin, R. (1994). L'eurolecte: Oui, jargon communautaire: Non. Meta: Translators' Journal, 39(4), 636-642.

de Groot, G.-R. (1988). Problems of legal translation from the point of view of a comparative lawyer. In P. Nekeman (Ed.), XIth World Congress of FIT: Proceedings (pp. 407-421). Maastricht: Euroterm.

Harvey, M. (2002.) What's so special about legal translation? Meta: Translators' Journal, 47(2), 177-185.

Heid, U., Fritzinger, F., Hauptmann, S., Weidenkaff, J., \& Weller, M. (2008). Providing corpus data for a dictionary for German juridical phraseology. In A. Storrer, A. Geyken, A. Siebert, \& K.-M. Würzner (Eds.), Text resources and lexical knowledge (pp. 133-144). Berlin: Mouton de Gruyter.

Hjort-Pedersen M., \& Faber, D. (2010). Explicitation and implicitation in legal translation: A process study of trainee translators. Meta: Translators' Journal, 55(2), 237-250.

Holmes, J. S. (1988b/2004). The name and nature of translation studies. In L. Venuti (Ed.), The translation studies reader (pp. 180-192, 2nd ed.).London: Routledge.

Kjær, A. L. (2007). Legal translation in the European Union: A research field in need of a new approach. In K. Kredens \& S. Goźdź-Roszkowski (Eds.), Language and the law: International outlooks (pp. 69-95). Frankfurt am Main: Peter Lang. 
Koskinen, K. (2008). Translating institutions: An ethnographic study of EU translation. Manchester: St. Jerome.

Lambert, J. (2009). The status and position of legal translation: A chapter in the discursive construction of societies. In F. Olsen, A. Lorz, \& D. Stein (Eds.), Translation issues in language and law (pp. 76-95). Basingstoke: Palgrave Macmillan.

L'Homme, M.-C., Heid, U., \& Sager, J. C. (2003). Terminology during the past decade (1994-2004): An editorial statement. Terminology, 9(2), 151-161.

McAuliffe, K. (2011). Hybrid texts and uniform law?: The multilingual case law of the Court of Justice of the European Union. International Journal for the Semiotics of Law, 24, 97-115.

Orozco, M., \& Sánchez-Gijón, P. (2011). New resources for legal translators. Perspectives: Studies in Translatology, 19(1), 25-44.

Pommer, S. (2006). Rechtsübersetzung und Rechtsvergleichung: Translatologische Fragen zur Interdisziplinarität. Frankfurt am Main: Peter Lang.

Pozzo, B. (2012). English as a legal lingua franca in the EU multilingual context. In C. J. W. Baaij (Ed.), The role of legal translation in legal harmonization (pp. 183-202). Alphen aan den Rijn: Wolters Kluwer.

Sandrini, P. (1996). Terminologiearbeit im Recht: Deskriptiver, begriffsorientierter Ansatz vom Standpunkt des Übersetzers. IITF Series 8. Wien: TermNet.

Šarčević, S. (1997). New approach to legal translation. The Hague: Kluwer Law International.

Šarčević, S. (2000). Legal translation and translation theory: A receiver-oriented approach. Genéve 2000: Actes www.tradulex.org.

Šarčević, S. (2007). Making multilingualism work in the enlarged European Union. In K. Kredens \& S. Goźdź-Roszkowski (Eds.), Language and the law: International outlooks (pp. 35-56). Frankfurt am Main: Peter Lang.

Šarčević, S. (2012). Challenges to the legal translator. In L. M. Solan \& P. M. Tiersma (Eds.), The Oxford handbook of language and law. Oxford: Oxford University Press. DOI: 10.1093/oxfordhb/9780199572120.013.0014.

Stubbs, M. (2004). Language corpora. In A. Davies \& C. Elder (Eds.), Handbook of applied linguistics (pp. 106-132). Oxford: Blackwell.

Temmerman, R. (2000). Towards new ways of terminology description: The sociocognitive approach. Amsterdam: John Benjamins.

Tessuto, G. (2008). Legal concepts and terminography: Analysis and application. In V. K. Bhatia, Ch. N. Candlin, \& P. Evangelisti Allori (Eds.), Language, culture and the law: The formulation of legal concepts across systems and cultures (pp. 283-302). Bern: Peter Lang.

Wolf, M., \& Fukari, A. (Eds.) (2007). Constructing a sociology of Translation. Amsterdam: John Benjamins. 